\title{
Review of Teaching Adult English Language Learners: A Practical Introduction
}

Sarah Young Knowles, TESOL Program, American University, Washington, D.C.

Two words stand out in the title of Betsy Parrish's second edition of this important volume: practical and introduction. In fact, practical is really an understatement for this accessible, useful, and relevant update to Parrish's original 2004 book. Teaching Adult English Language Learners provides research- and practice-based guidance, recommendations, and examples for novice and experienced teachers alike. Graduate students, community-based volunteers, teacher educators, program directors, and classroom teachers will all gain informative background knowledge about the field of adult ESL while also finding hands-on activities that can be put immediately to use with adult English language learners.

The core themes of this second edition remain the same as the first edition. Key takeaways from both editions include a focus on knowing and responding to learners' needs, teaching language for meaningful purposes, and using interactive activities to facilitate English language acquisition in the classroom. The 2019 edition is still full of sample lesson plans, activity ideas, templates, teacher vignettes, charts, reflective prompts, resources, and "scripts" for effective teacher talk, many of which are completely new here.

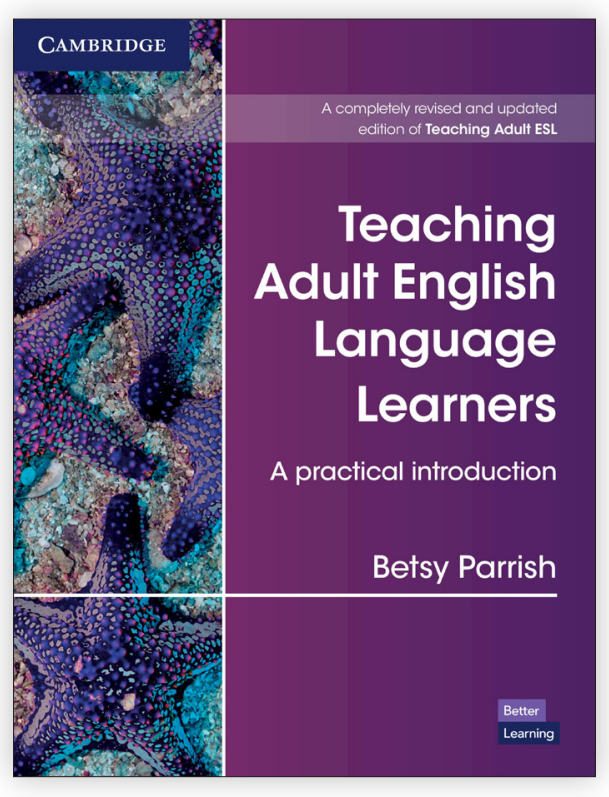

adult English language learners. Chapter 8, which focuses on the selection and use of instructional materials, highlights new teaching and learning technologies that require equal attention to language and digital literacy skills. Chapter 
10 explains in clear and comprehensive terms how new guidelines, such as the English Language Proficiency Standards for Adult Education in the United States and the Australian Core Skills Framework, can be useful at both the programmatic level and the practitioner level for designing and assessing learning outcomes.

Throughout the book, we also see connections being made to more contemporary concepts in applied linguistics. In Chapter 6, Parrish encourages translanguaging practices as an effective alternative to English-only classroom policies. In Chapter 7, she shares trauma-informed educational practices for working with victims of abuse, war, or other traumatic experiences. In Chapter 8 , she explains how adult English language learners can benefit from the integration of language learning and new core digital competencies, going beyond the now simplistic "computer-assisted language learning" approach of the early 2000 .

Parrish's voice in this revised edition remains thoughtful, friendly, and inviting. She is the perfect companion for practicing teachers who work through the book on their own, either individually or as part of a study circle, and for teacher educators who assign readings from the book. At the end of each chapter, there are suggestions for further exploration or practice that are targeted to both pre-service teachers and in-service teachers. These summative activities guide the reader to examine their own beliefs and practices while applying new strategies and ideas from the book.

Readers are also encouraged to explore additional resources available from the publisher's website, all of which are free, easily accessible, and updated occasionally by Parrish herself. Although they are not included directly in the book, these supplementary resources open up a door into the larger community of adult ESL practitioners, researchers, and policy makers. Teaching toolkits, videos, study circle guides, research reports, and practice briefs will introduce readers to many other timely options for professional development.

Those of us who are familiar with the original edition might notice that there has been a small revision to part of the book's title itself: Teaching Adult ESL (2004) has changed to Teaching Adult English Language Learners (2019). At first glance, this change may seem insignificant, but I believe that it speaks to the core philosophy of Parrish's approach. She wants the learners themselves - along with their needs, interests, and goals - to be at the center of teachers' classroom practice.

Although Parrish's book is already comprehensive, I found myself wondering if there is a place in the book to address employment opportunities as well as employment concerns in the field of adult ESL. In the United States, full-time, well-paid jobs in adult education are few and far between. Graduate programs are time-intensive and costly. Many teachers are drawn to the field because they love what they do, but leave when they face the realities of job security and salary. Parrish cannot change this reality, but it is worth acknowledging and connecting readers to advocacy efforts currently in place.

Teaching Adult English Language Learners: A Practical Introduction belongs on every adult ESL teacher's bookshelf (or electronic device!) as required reading. In this book, Parrish serves as an informed mentor, a collaborative colleague, and a bridge-builder between research and practice. When she writes the next edition, I suggest that she replace the word Introduction in the book's title with Compendium or Encyclopedia. Her book does not just skim the surface, but rather provides a thorough blueprint for high quality adult ESL programming, classroom instruction, and professional development. 